\title{
Международная научная конференция „XIII international conference on hole burning, single molecule, and related spectroscopies: science and applications (HBSM-2018)“
}

\author{
(C) A.B. Наумов ${ }^{1,2}$, К.P. Каримуллин ${ }^{1,2}$ \\ ${ }^{1}$ Институт спектроскопии РАН, \\ 108840 Троицк, Россия \\ ${ }^{2}$ Московский педагогический государственный университет, \\ 119991 Москва, Россия \\ e-mail: naumov@isan.troitsk.ru
}

Поступила в редакцию 24.09.2018 г.

13-я международная научная конференция HBSM2018 „Hole Burning, Single Molecule, and Related Spectroscopies: Science and Applications" (Выжигание спектральных провалов, спектроскопия одиночных молекул и смежные методы: наука и приложения) была проведена Институтом спектроскопии РАН (ИСАН, лаборатория электронных спектров молекул) в сотрудничестве с Московским педагогическом государственным университетом (МПГУ, кафедра теоретической физики имени Э.В. Шпольского) с 6 по 10 августа 2018 г. в г. Суздале Владимирской области и 11 августа в г. Москве. Председатель организационного комитета конференции - заведующий отделом спектроскопии конденсированных сред ИСАН, заведующий кафедрой теоретической физики МПГУ, доктор физ.-мат. наук, профессор РАН Андрей Витальевич Наумов; ученый секретарь - кандидат физ.-мат. наук, с.н.с. ИСАН, заведующий лабораторией МПГУ Камиль Равкатович Каримуллин. В организации и проведении мероприятия приняли активное участие сотрудники ИСАН, а также студенты и аспиранты МПГУ, МФТИ и ВШЭ. Финансовую поддержку оказал Российский фонд фундаментальных исследований (проект № 18-02-20081). Официальный сайт конференции: www.hbsm2018.ru.

В работе конференции приняли участие специалисты научно-исследовательских институтов и высших учебных заведений России (79 человек) и представители зарубежных научно-исследовательских организаций и университетов (65 человек) - всего 144 участника (из них - 70 молодых ученых, студентов и аспирантов в возрасте до 35 лет). Представлено: 3 пленарных лекции, 19 приглашенных докладов, 34 устных и 41 стендовый доклад - всего около 200 соавторов из 116 организаций из 21 страны (Австралия, Беларусь, Бельгия, Германия, Дания, Израиль, Индия, Италия, Канада, Китай, Нидерланды, Польша, Россия, Сербия, США, Украина, Франция, Швейцария, Швеция, Эстония, Япония).

Приоритет России в разработке методов селективной лазерной спектроскопии признан во всем мире. В 1952 г. сотрудники кафедры теоретической физики Московского государственного педагогического института под руководством профессора Эдуарда Владимировича Шполь- ского впервые наблюдали возникновение квазилинейчатых спектров сложных органических соединений при низких криогенных температурах в специально подобранных растворителях, ныне известных как матрицы Шпольского. В 1972 г. научная группа под руководством ученика Э.В. Шпольского, одного из основателей Института спектроскопии АН CCCP, профессора Романа Ивановича Персонова, провела первые эксперименты по селективному лазерному возбуждению спектров люминесценции органических молекул. Затем в 1974 г. исследователи из группы Р.И. Персонова и их коллеги из Института физики в Тарту провели основополагающие эксперименты по выжиганию стабильных спектральных провалов. Все эти работы легли в основу нового научного направления - селективной лазерной спектроскопии, кульминацией которого стала спектроскопия одиночных молекул (см. обзор Наумов А.В. // УФН. 2013. T. 183. № 6. C. 633. doi 10.3367/UFNr.0179.200903n.0322; Naumov A. V. // Physics Uspekhi. 2013. V. 56. N 6. P. 605. doi 10.3367/UFNe.0183.201306f.0633).

Конференция впервые была организована в 1987 г. в Таллине как „Всесоюзный симпозиум по современным методам лазерной спектроскопии молекул в низкотемпературных средах“. В последующие годы конференция проводилась за рубежом под разными названиями: „Выжигание спектральных провалов“ (Монтерей, США, 1991), „Выжигание спектральных провалов и возбуждение тонкоструктурных спектров люминесценции“ (Аскона, Швейцария, 1992), „Выжигание спектральных провалов и смежные методы“ (Токио, Япония, 1994; Брейнерд, США, 1996; Хуртин, Франция, 1999). В 2001 г. конференция получила свое текущее наименование „Выжигание спектральных провалов, спектроскопия одиночных молекул и смежные методы: наука и приложения“ (HBSM). Последующие конференции проходили с периодичностью в три года в Тайбэе (Тайвань, 2001), Боземане (США, 2003), Аусуа (Франция, 2006), Палм-Коув (Австралия, 2009), Тюбингене (Германия, 2012) и Тарту (Эстония, 2015). Серия конференций HBSM успешно объединяет участников из ведущих исследовательских групп по всему миру для обсуждения 
актуальных фундаментальных и прикладных вопросов в области селективной лазерной спектроскопии.

Доклады на HBSM-2018 были объединены в несколько тематических научных секций.

Открытие конференции было ознаменовано вручением премии имени Шпольского-Ребане-Персонова, которая была учреждена в 2018 г. Институтом физики Университета Тарту (Эстония), Институтом спектроскопии РАН и Московским педагогическим государственным университетом. Первая медаль ШпольскогоРебане-Персонова и денежный приз по решению международного комитета были вручены профессору Fedor Jelezko (Ulm University, Германия) за экспериментальные исследования по квантовой оптике с одиночными молекулами и NV-центрами в алмазах и их применения для магнитометрии и квантовой информатики. После награждения профессор F. Jelezko выступил с пленарной лекцией „Diamond based Quantum Technologies“.

В качестве пленарных докладчиков конференции выступили ученые мирового уровня: лауреат Нобелевской премии по химии 2014 г. профессор William Moerner (Stanford University, США), прочитавший лекцию на тему ,Single molecules across the decades, from low temperature, to 3D imaging and tracking in sells, to solution photodynamics“, и лауреат международной премии Эдисона Вольты профессор Michel Orrit (Leiden University, Нидерланды), выступивший с лекцией „Looking back on 28 years of cryogenic single-molecule experiments". Пленарные лекции У. Мернера и М. Оррита состоялись 11 августа в Главном здании МПГУ после торжественной церемонии присвоения ученым звания „Почетный профессор МПГУ“ (более подробную информацию и видеозапись см. на сайте МПГУ по адреcy http://mpgu.su/novosti/vyidayushhie-uchenyie-u-merner-im-orrit-stali-pochetnyimi-professorami-mpgu/).

На заседаниях секции „Фотоиндуцированные явления в твердых телах“ рассматривались вопросы, связанные с исследованиями в области селективной лазерной спектроскопии, выжигания спектральных провалов, фотофизики биомолекул и молекулярных комплексов, фотонного эха и ультрабыстрых процессов, оптической дефазировки и спектральной диффузии. С приглашенными докладами выступили: проф. Aleksander Rebane (Montana State University, США) „Multiphoton spectroscopy: An optical window into molecular electrostatics“, проф. Ryszard Jankowiak (Kansas State University, CШA) „Impact of Single Point Mutations on the Excitonic Structure and Dynamics in FennaMatthews-Olson Complex“, проф. Miroslav Dramićanin (University of Belgrade, Сербия) „Comparison of Different Schemes for Temperature Readout from Luminescence“, проф. Ivan Shcheblykin (Lund University, Швеция) „Non-radiative Processes in Metal Halide Perovskite Semiconductors Probed by Photoluminescence Microscopy ${ }^{\text {“ }}$ и Ilya Akimov (Technische Universit.t Dortmund, Германия) „Photon Echoes and Coherent Magneto-optical
Phenomena in Semiconductors“". С интересными устными докладами выступили: проф. Александр Мишин (Институт биоорганической химии им. академиков М.М. Шемякина и Ю.А. Овчинникова PАН) „Livecell nanoscopy enabled with transient labeling and the control of fluorophore blinking“", проф. Hiroshi Murakami (National Institutes for Quantum and Radiological Science and Technology, Япония) „Site-selective spectroscopy of nanoconfined dye molecules in liquid and at room temperature“, проф. Олег Хасанов (НПЦ по материаловедению НАН Беларуси) „Тime resolved femtosecond spectroscopy of nanocomposites", проф. Игорь Осадько (Институт спектроскопии PAH) „FRET in single donoracceptor pair attached to a biomolecule as a nano-ruler", Masaru Oda (Kyushu Institute of Technology, Япония) „Synthesis and PL Properties of Quantum-dot Chains: Gel Electrophoresis and Hybridization of DNA-functionalized Quantum-dots“, проф. Александр Старухин (Институт физики им. Б. И. Степанова НАН Беларуси „Influence of Solid Matrices on Spectral Features of Metalloporphyrins".

Заседания тематической секции „Одиночные наносистемы и нанооптика“ были посвящены обсуждению следующих научных проблем: спектроскопия одиночных молекул и наночастиц; одиночные биомолекулы и квантовые точки; одиночные ионы и центры окраски в твердых телах и нанокристаллах; наноскопия; спектроскопия ближнего поля и наноплазмоника; нелинейные оптические эффекты. С приглашенными докладами выступили: проф. Jürgen Köhler (University of Bayreuth, Германия) „Light Controls Light: Single Molecules as Optical Switches", проф. Andrey Evlyukhin (University of Southern Denmark, Дания) „Optical Resonances of Si-nanoparticles for Dielectric Photonics“, проф. Alfred Meixner (University of Tübingen, Германия) „Half-wavelengths Fabry Pérot Micro-resonators in Single Molecule Spectroscopy“", проф. Thomas Basché (Johannes Gutenberg-Universitet Mainz, Германия) „Imaging and Force Transduction in Correlative Scanning Force and Confocal Fluorescence Microscopу“ и и поф. Martin Vacha (Tokyo Institute of Technology, Япония) „Photophysics and Electroluminescence of Single Nanocrystals of Halide Perovskites and Related Nanomaterials“. Среди устных сообщений, представленных в данной секции, можно выделить доклады: проф. Zoran Ristanovic (Leiden University, Нидерланды) „Large Linear Stark Effect on Single Molecules of Dibenzoterrylene in Crystals of Substituted Naphthalenes“, Максима Гладуша (Институт спектроскопии РАH) „Local and Macroscopic Characterization with Single Molecules and Single Quantum Emitters", проф. Boleslaw Kozankiewicz (Institute of Physics PAS, Польша) „Anomalous Doping of a Molecular Crystal Monitored at the Single-Molecule Level“. Стоит отметить активность молодых участников, представивших результаты своих исследований: Frank Wackenhut (University of Tübingen, Германия) „Multi-photon Luminescence of Single Gold Nanoparticles: Exploring the Dynamics of Plasmons and Electron Hole Pairs“, Алексея Шайманова 


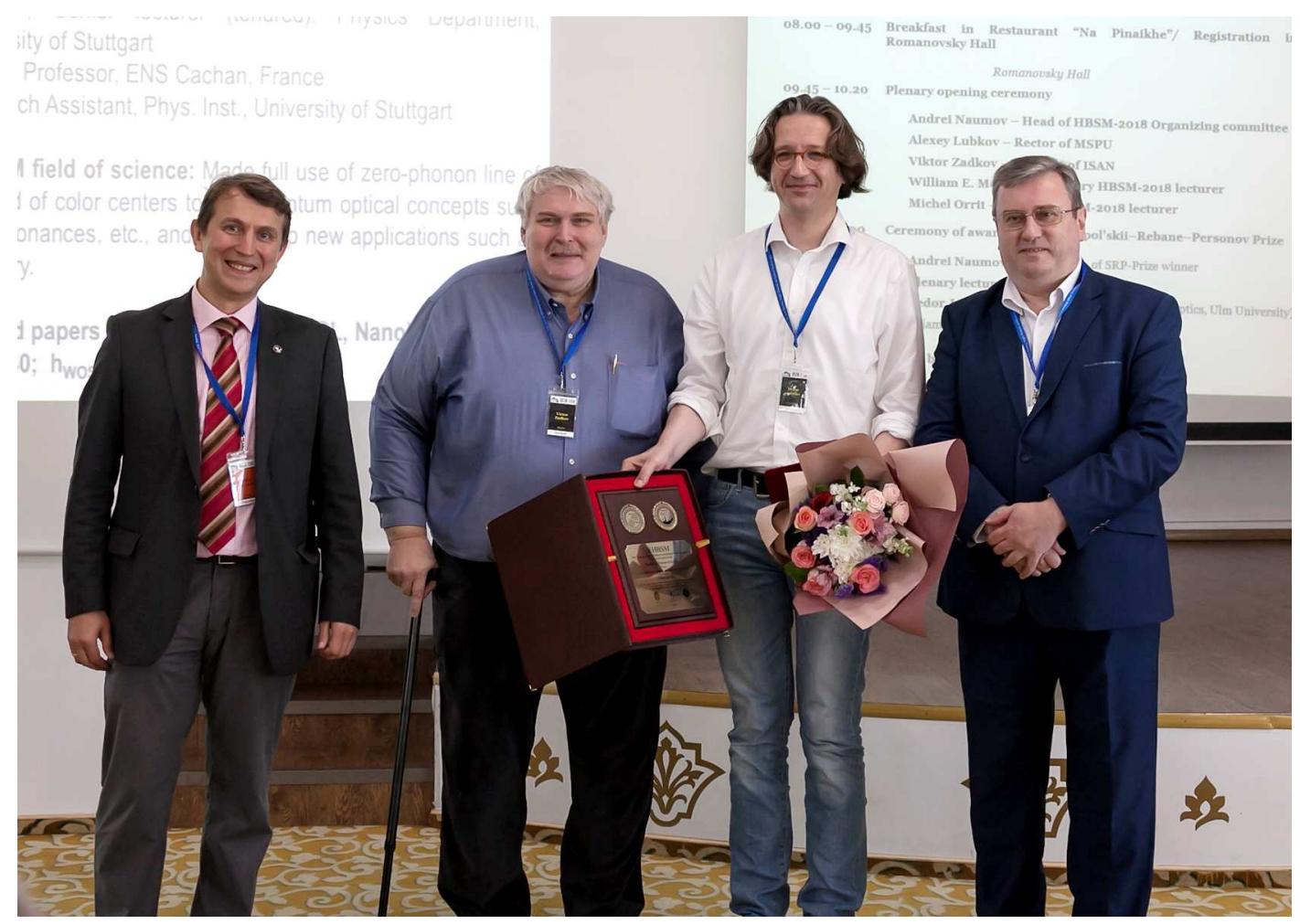

Награждение первого лауреата Премии Шпольского-Ребане-Персонова. Слева направо: председатель программного комитета конференции, зав. отделом ИСАН, зав. кафедрой МПГУ, д.ф.-м.н., проф. Наумов А. В.; директор ИСАН д.ф.-м.Н., проф. Задков В. Н.; победитель конкурса на соискание Премии Шпольского-Ребане-Персонова 2018 г. проф. Fedor Jelezko (Ulm University, Германия); ректор МПГУ д.и.н., чл.-корр. РАО Лубков А.В.

(ФГУП „ВНИИА“) „Plasmonic Magneto-optical Nested 2D Nanostructures: Tailoring Responses through Effective Refractive Index“, Михаила Губина (Владимирский государственный университет, МПГУ) „Entangled Plasmon Generation in Nonlinear Spaser Systems", Ивана Еремчева (Институт спектроскопии PAH) „Fluorescence Nanoscopy of Single Quantum Dot Pairs".

На заседаниях секции „Функциональные наноматериаль“"обсуждались оптические маркеры, органические и неорганические системы, фотовольтаические приложения; гибридные системы; сенсоры на основе одиночных молекул и наночастиц. Приглашенные доклады были представлены проф. Vahid Sandoghdar (Max Planck Institute for the Science of Light, Германия) „Organic Molecules Coming of Age in Quantum Optics“и проф. Taras Plakhotnik (The University of Queensland, Австралия) „Investigation of Evaporation of Sessile Droplets Using Luminescent Nano-probes and other Applications of NV Centers in Diamond“. С устными докладами выступили проф. Anshel Gorokhovsky (City University of New York, CШA) „Ion Implanted Defects in Diamond: Optical Spectroscopy of the Xe Center" и Алла Генералова (Институт биоорганической химии им. академиков М.М. Шемякина и Ю.А. Овчинникова РАН) „Uрconversion Nanoparticles: on the Way from Diagnostics to Theranostics“, а также молодые ученые из России:
Вадим Воробьев (ФИАН) „Теmperature related shift in the hyperfine structure of NV center ground state“, Евгений Хайдуков (Институт фотонных технологий РАН) „Emerging Upconversion Nanoparticles for Industry and Biomedical Application“ и К Кирилл Прусаков (Национальный медицинский исследовательский центр онкологии имени Н.Н. Блохина) „Thin Layer Fluorescence Microscopy Based on One-dimensional Photonic Crystal"“

На заседаниях секции „Оптическая обработка информации и квантовые технологии“ были представлены исследования в области твердотельной оптической памяти и квантовой информатики, голографической и пространственной записи информации, интегрированных технологий, новых спектроскопических методов и инструментов. Прозвучали приглашенные доклады проф. Gerd Leuchs (Max Planck Institute for the Science of Light, Германия) „Optical Interface for a Single Atom in Free Space“, проф. Анатолия Андреева (МГУ) „Longitudinal Current in Single-atom Interacting with Laser Field“, проф. Pavel Bushev (Saarland University, Германия) „Coherent Spin Dynamics of Erbium Doped Crystals at Sub-Kelvin Temperatures", проф. Philippe Goldner (Chimie ParisTech, Франция) „Long lived Optical and Spin Coherences in Rare Earth Doped Nanomaterials“" и проф. Григория Гольцмана (МПГУ, КФТИ КазНЦ РАН) „Quantum Photonic Integrated Circuits with Waveguide Integrated 


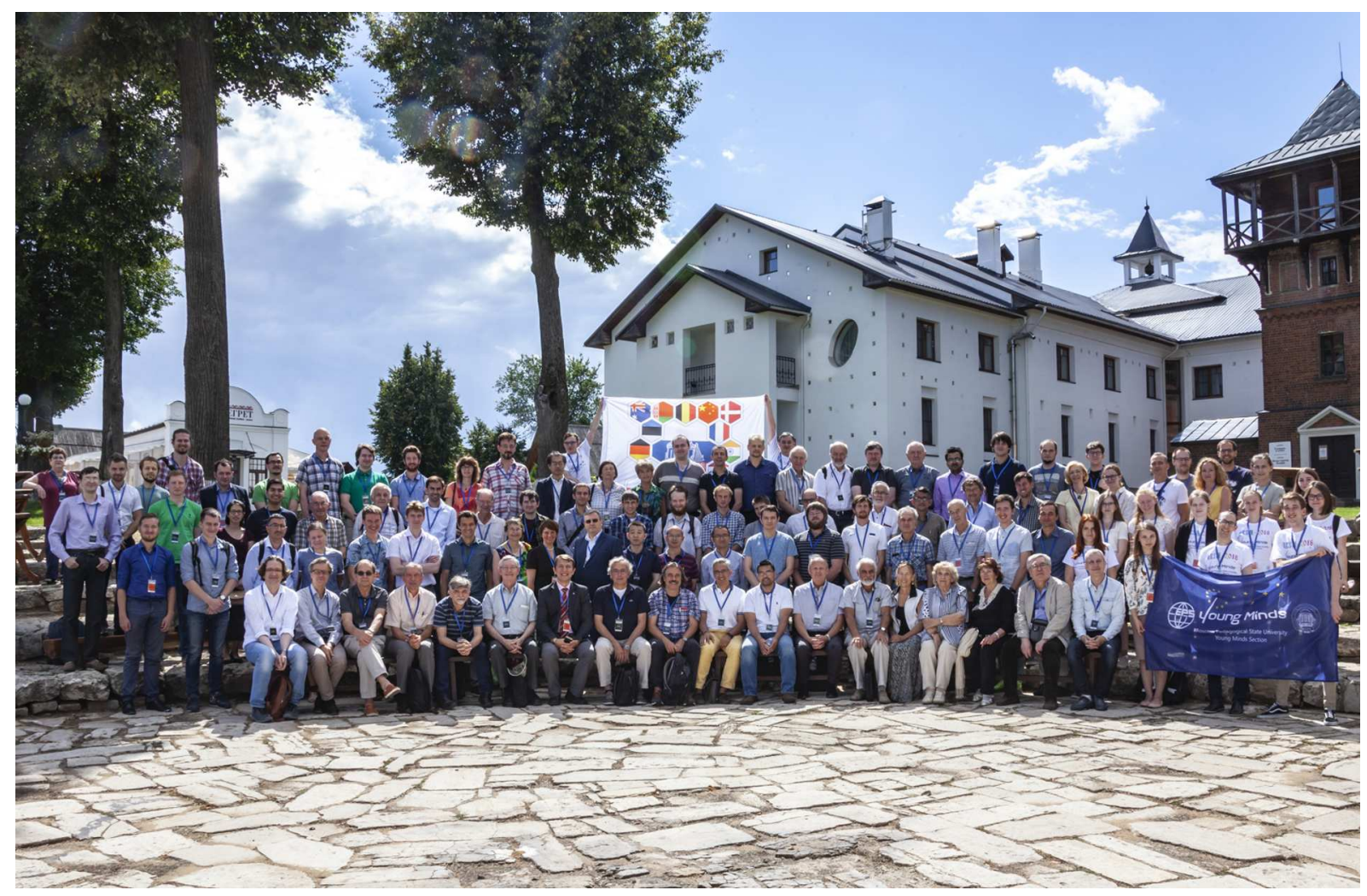

Общая фотография участников конференции HBSM-2018.

Super-conducting Nanowire Single-photon Detectors“. Устные доклады представили: проф. Светлана Котова (Самарский филиал ФИАН) „New schemes of Compact Modal LC modulators for Control of Light Spatial Structure“, Евгений Васильев (МГУ) „Multifocus Selffocusing of a Femtosecond Optical Vortex“", Alexey Tiranov (University of Geneva, Швейцария) „Spectroscopy of Rare-earth Ion-doped Crystals for Optical Quantum Memory Applications“, Manjin Zhong (The Australian National University, Австралия) „Study of the Dynamics of the Nuclear Spin Bath in Europium-doped Yttrium Orthosilicate“ и Sacha Welinski (Institut de Recherche de Chimie Paris, Франция) „Simultaneous Coherence Enhancement of Optical and Microwave Transitions in ${ }^{171} \mathrm{Yb}: \mathrm{Y}_{2} \mathrm{SiO}_{5}{ }^{6}$.

Для молодых участников конференции была организованы заседания стендовой секции и конкурс научных докладов. Председателем жюри выступил проф. Ivan Scheblykin (Lund University, Sweden). По итогам конкурса дипломом за лучший стендовый доклад был награжден Андрей Анисимов (ФТИ им. А.Ф. Иоффе РАН, Санкт-Петербург), a Alexey Tiranov (University of Geneva, Швейцария) был награжден за лучший устный доклад. Отдельное мероприятие для молодых исследователей было организовано в формате „круглый стол“ при поддержке Европейского физического общества и благодаря активному участию молодежной секции
EPS „Moscow Pedagogical State University Young Minds Section".

11 августа участники конференции были приглашены в Институт спектроскопии РАН, где состоялось заседание специальной исторической секции, посвященной 50-летнему юбилею института. Гостей поприветствовал глава города В.Е. Дудочкин. Директор ИСАН проф. В.Н. Задков в своем обзорном докладе рассказал об истории и современной деятельности института. С краткими научными сообщениями выступили чл.-корр. РАН проф. Е.А. Виноградов и проф. В.М. Агранович. Приглашенный гость, бывший сотрудник ИСАН проф. Борис Харламов поделился воспоминаниями о первых работах по селективной лазерной спектроскопии, выполнявшихся в институте под руководством профессора Р.И. Персонова. Во время перерыва гости получили возможность познакомиться с лабораториями института.

На закрытии HBSM-2018 Уильям Мёрнер от имени всех участников поблагодарил команду организаторов во главе с А.В. Наумовым за радушный прием и высокий уровень проведенной конференции. По решению международного программного комитета очередная конференция „Выжигание спектральных провалов, спектроскопия одиночных молекул и смежные методы: наука и приложения“ (HBSM-2021) пройдет в замке Банц (БадШтаффельштайн, Бавария, Германия) в 2021 г. 